\title{
АКТУАЛИЗАЦИЯ ДИСТАНЦИОННОЙ ЗАНЯТОСТИ В ПЕРИОД ПАНДЕМИИ
}

\author{
(c) 2021 Лагутина Лариса Геннадьевна \\ кандидат экономических наук \\ кафедра бухгалтерского учета и налогообложения \\ Российский экономический университет имени Г. В. Плеханова, Россия, Москва \\ E-mail: larisalagutina@mail.ru
}

Пандемия, вызванная распространением коронавирусной инфекции, повлияла на характер трудовых отношений. Требование соблюдения режима самоизоляции способствовало развитию дистанционной занятости. В данной статье рассматриваются потенциальные выгоды для предприятий от привлечения сотрудников на дистанционную работу, а также правовая сторона взаимоотношений работников и работодателей. Отдельное внимание уделяется вопросу компенсации затрат сотрудников в связи с выполнением ими своей трудовой функции.

Ключевые слова: дистанционная занятость, дистанционная работа, затраты, пандемия, человеческий капитал, трудовые отношения, налогообложение.

Активно развивающиеся последние десятилетия компьютерные технологии существенно изменили формы взаимодействия между людьми, оказав влияние на характер трудовых отношений. Присутствие работника в конкретном месте для выполнения его обязанностей стало необязательным условием для достижения успешного результата. На смену традиционным трудовым отношениям пришла дистанционная форма занятости.

В период пандемии, вызванной распространением вируса SARS-CoV-2, в условиях соблюдения режима самоизоляции, дистанционная занятость затронула большинство отраслей экономической деятельности человека, обнаружив не только преимущества для работника и для работодателя, но и немало проблем. В то же время это не помешало дистанционной форме организации труда стать достаточно распространенным видом занятости и в условиях частичного снятия ограничений.

Проблемы дистанционной занятости работников и перспективы ее развития рассматриваются такими исследователями как Нацыпаева Е.А.[5], Новикова Н.М.[6], Закалюжная Н.В.[3], Лютов Н.Л.[4], Брюхина Е.P.[1].

В рамках рассмотрения проблем дистанционной занятости важными вопросами, подлежащими исследованию, являются:

- ее преимущества и недостатки;

- правовое регулирование взаимоотношений работника и работодателя;

- компенсация затрат, связанных с выпол- нением трудовой функции;

- налоговый учет компенсационных выплат работникам.

Дистанционная форма занятости предусмотрена трудовым законодательством. Так, согласно статье 312.1 Трудового кодекса Российской Федерации (далее - ТК РФ), дистанционная работа - это выполнение определенной трудовым договором трудовой функции вне места нахождения работодателя при условии использования для выполнения данной трудовой функции и для осуществления взаимодействия между работодателем и работником по вопросам, связанным с ее выполнением, информационно-телекоммуникационных сетей, в том числе сети «Интернет», и сетей связи общего пользования.

Дистанционная занятость позволяет интегрироваться в трудовую деятельность более широкому кругу лиц, в частности лицам с ограниченными физическими возможностями, работникам пенсионного возраста за счет использования своего трудового потенциала «вне офиса» [6, 153], женщинам в декрете.

Важным преимуществом является возможность установить трудовые отношения с работодателями, территориально расположенными в иной местности, вне места проживания работника: как в других городах, так и странах.

В 70-ых годах XX века появившаяся теория человеческого капитала ввела в рассмотрение такие факторы экономического развития как знания, образование человека, а также его трудовую мобильность. Так Галенко В.П. и Плис К.С. 
отмечают, что «переезд людей на постоянное место жительства в другие страны способствует долговременному переносу человеческого капитала (в виде знаний и умений высококвалифицированных специалистов) в принимающие государства, что в конечном счете находит свое выражение в увеличении доходности бизнеса» [1, 1092].

В настоящее время трудовая мобильность может быть обеспечена не только путем физического перемещения в пространстве, но и использованием сети Интернет и применением мобильных устройств. Очевидно, что открывающиеся возможности необходимо использовать для наращивания интеллектуального потенциала предприятий.

Привлечение дистанционных работников дает компаниям немало дополнительных преимуществ [7]. Отсутствие необходимости организовывать рабочие места на территории работодателя позволяет сократить ряд затрат, например, расходы на аренду помещений, компьютерную технику, электроэнергию, коммунальные услуги. Кроме того, в периоды высокой заболеваемости работники имеют меньше социальных контактов, что сокращает вероятность наступления периодов их временной нетрудоспособности. В свою очередь, работники могут организовывать свою трудовую деятельность самостоятельно, соблюдая баланс между личной жизнью, семейными обязанностями и работой. Это бесспорно повышает лояльность к работодателю.

Однако серьезной проблемой дистанционного труда выделяют «риск сверхэксплуатации дистанционных работников», связанного с тем, что в условиях отсутствия со стороны работодателя возможности контроля процесса труда не учитывается фактически отработанное время [4, 32]. Другим следствием отсутствия контроля может стать несоблюдение трудового распорядка со стороны работников, а также неспособность организовать свою работу. Перечисленные проблемы могут быть частично устранены четкой регламентацией деятельности сотрудников в рамках правового поля, определенного трудовым законодательством.

Согласно Трудовому кодексу Российской Федерации, дистанционная работа может носить постоянный или временный характер.

Постоянная дистанционная работа осуществляется на протяжении всего срока действия трудового договора, продолжительность которого не ограничена. В то же время временная дис- танционная работа может быть непрерывной или периодической. Непрерывная работа осуществляется в течение определенного трудовым договором или дополнительным соглашением к трудовому договору срока, не превышающего шести месяцев. Периодическая - предусматривает чередование периодов выполнения работником трудовой функции дистанционно и периодов выполнения им трудовой функции на стационарном рабочем месте.

Перевод на временную дистанционную работу, как правило, осуществляется по инициативе работодателя. Законодательством предусмотрено право перевода сотрудников на такую форму занятости в случаях, предусмотренных статьей 312.9 ТК РФ, например:

- катастрофы природного или техногенного характера,

- производственной аварии,

- несчастных случаев на производстве,

- пожара, наводнения, землетрясения,

- эпидемии или эпизоотии и в любых исключительных случаях, ставящих под угрозу жизнь или нормальные жизненные условия всего населения или его части.

В этом случае составляется локальный нормативный акт, определяющий порядок и способы взаимодействия работника и работодателя в отношении обмена информацией и передачи результатов труда, режим рабочего времени, сроки, в течение которых работник обязан отвечать на запросы работодателя, связанные с выполнением трудовой функции, порядок ознакомления работника с документами, связанными с его трудовой деятельностью.

Согласно статье 312.6 ТК РФ работодатель должен обеспечить дистанционного работника необходимыми для работы оборудованием, программно-техническими средствами, средствами защиты информации и т.д. При этом дистанционный работник вправе для исполнения своих трудовых обязанностей использовать собственное или арендованное им оборудование и принадлежащее ему программное обеспечение. В этом случае работодатель должен выплатить компенсацию.

Для этого в трудовом договоре или локальном нормативном акте должны быть предусмотрены:

- размер, порядок и сроки выплаты компенсации;

- порядок возмещения других расходов, 
связанных с выполнением дистанционной работы, например, расходов на интернет, телефонную связь и т.д.

Отказ работодателя компенсировать затраты работника является нарушением. При этом невозможно предусмотреть в трудовом договоре или локальном нормативном акте условие о том, что расходы, связанные с дистанционной работой, не возмещаются. За невыплату компенсации, работодатель несет материальную и административную ответственность.

В соответствии со статьей 236 ТК РФ материальная ответственность предполагает выплату, помимо задолженности, сумму процентов в размере не ниже 1/150 действующей в это время ключевой ставки ЦБ РФ от невыплаченной в срок суммы за каждый день задержки.

В рамках административной ответственности может быть наложен штраф:

- от 10000 до 20000 рублей на должностных лиц;

- на лиц, осуществляющих предпринимательскую деятельность без образования юридического лица, - от 1000 до 5000 рублей;

- на юридических лиц - от 30000 до 50000 рублей (ч. 6 статьи 5.27 КоАП РФ).

Размер компенсации определяется работодателем самостоятельно. Он может быть установлен в фиксированной сумме или рассчитываться по определенному алгоритму, например, в зависимости от количества используемого оборудования, программного обеспечения, средств защиты информации.

Возмещение расходов, связанных с выполнением дистанционной работы, в том числе расходов на использование сети Интернет, оплату электроэнергии, может осуществляться на основании документов, подтверждающих фактическое несение расходов и их размер.

Сроки выплаты и размеры компенсации и возмещения расходов законодательством не регламентированы, поэтому должны быть установлены любым из следующих документов:

- коллективным договором;

- локальным нормативным актом;

- трудовым договором или дополнительным соглашением к нему.

Порядок выплаты сумм компенсации и возмещения расходов может быть аналогичен порядку выплаты заработной платы.

Суммы выплачиваемой работникам компенсации и суммы возмещения расходов включают- ся в налоговую базу по налогу на прибыль организаций. Об этом, в частности, отмечалось в писыме ФНС России от 12.02.2021 N СД-4-11/1705@.

Согласно пункту 1 статьи 252 НК РФ расходы должны быть обоснованными, то есть экономически оправданными, иметь денежное выражение, документально подтверждены и направлены на получение дохода.

К подтверждающим документам относятся:

- документы, устанавливающие порядок, сроки и размер выплат (трудовой договор, дополнительное соглашение к трудовому договору, коллективный договор, локальный нормативный акт работодателя);

- копии документов, подтверждающие приобретение (аренду) оборудования работником, а также расчеты компенсаций и документы, подтверждающие фактическое использование имущества в интересах работодателя;

- копии документов о расходах, понесенных работником при использовании этого имущества в служебных целях.

В целях налогообложения налогом на прибыль в соответствии со статьей 255 НК РФ указанные расходы относятся к расходам на оплату труда, как компенсационные начисления, связанные с режимом работы или условиями труда, предусмотренные нормами законодательства Российской Федерации, трудовыми договорами или коллективными договорами.

В то же время указанные суммы не облагаются налогом на доходы физических лиц, так как согласно пункту 1 статьи 217 НК РФ не подлежат налогообложению все виды компенсационных выплат, установленных законодательством. Кроме того, на основании положений пп. 2 п. 1 статьи 422 НК РФ они не подлежат обложению страховыми взносами.

Таким образом, пандемия привела к изменению привычных взаимосвязей, сложившихся на предприятиях с сотрудниками и вызвала распространение дистанционной занятости, открывающей немало возможностей для предприятий, а именно:

- вовлечение в трудовые отношения лиц, для которых не подходят традиционные формы занятости;

- возможность найма высококвалифицированных или уникальных специалистов, проживающих на удаленных от предприятия территориях;

- оптимизацию затрат, связанных с организацией труда. 


\section{Библиографический список}

1. Брюхина E.P. Дистанционная (удаленная) работа как цифровой сегмент рынка труда: проблемы и перспективы. // Вестник Воронежского государственного университета. Серия: Право. 2021. № 1 (44). С. 80-89.

2. аленко В.П., Плис К.С. Мобильность человеческого капитала как фактора повышения устойчивости экономического развития предприятия и страны. // Креативная экономика. 2018. Т. 12. №8. С. 1089-1096.

3. Закалюжная Н.В. Дистанционная работа и схожие правоотношения // Право. Журнал Высшей школы экономики. 2015. № 2. С. 76-91.

4. Лютов Н.Л. Дистанционный труд: опыт Европейского союза и проблемы правового регулирования в России // Lex Russica (русский закон), 2018, № 10 (143), с. 30-39.

5. Нацыпаева Е.А. Дистанционная работа бизнеса: проблемы перехода и перспективы развития // Экономическая безопасность и качество. 2020. № 2 (39), С. 100 - 103.

6. Новикова М.В. Дистанционный труд. Преимущества дистанционной занятости. Вестник Национального института бизнеса. 2020. № 39. С. 152-158.

7. Шестакова Е.В. Особенности регулирования труда дистанционных работников. Правовой комментарий «Право Доступа», 2021 г. 